\title{
Clinical, pathological, radiological characteristics, risk stratification and immunohistochemistry profile of gastrointestinal stromal tumors treated in a tertiary cancer centre located in Sub-Himalayan region: institutional experience of 20 patients and review of literature
}

\author{
Jyoti Sharma*, Anup Negi, Manish Gupta, \\ Vikas Fotedar, Siddharth Vats, Pravesh Dhiman
}

Department of Radiotherapy, IGMC, Shimla, Himachal Pradesh, India

Received: 06 June 2021

Revised: 09 July 2021

Accepted: 12 July 2021

\author{
*Correspondence: \\ Dr. Jyoti Sharma, \\ E-mail: jyotisharma217@gmail.com
}

Copyright: () the author(s), publisher and licensee Medip Academy. This is an open-access article distributed under the terms of the Creative Commons Attribution Non-Commercial License, which permits unrestricted non-commercial use, distribution, and reproduction in any medium, provided the original work is properly cited.

\begin{abstract}
GIST (gastrointestinal stromal tumors) are the rare mesenchymal tumors. Treatment includes curative surgery along with targeted agents like TKI in neoadjuvant/adjuvant settings. A total of 20 patients of histology proven GIST who were registered between 2014 to 2020 were reviewed for clinico-pathological data, endoscopic and radiological investigations, sites, primary treatment received, histology, immunohistochemistry, stage, risk stratification and imatinib therapy. GIST was more common in males than females. Age group varied between 25 years to 76 years. Majority of patients consumed non vegetarian diet, half of them being smokers and consumed alcohol. Pain abdomen, abdominal lump, dysphagia, haematemesis, melena and blood in stools were presenting complaints. CECT revealed heterogeneously enhancing mass with necrosis as most common finding. Upper GI endoscopy/colonoscopy revealed extrinsic bulge, polypoidal growth or ulcers as main findings. Stomach was the most common site followed by jejunum. Few patients presented with metastatic disease to liver and lungs. HPE revealed spindle cell GIST as main histology (with one patient with mixed spindle and epithelioid cells) with all patients having immunoreactivity to CD117. Majority of patients belonged to stage III and high-risk category by NIH stratification criteria. In majority of patients treatment received was surgery followed by adjuvant imatinib. Few patients had unresectable disease at presentation and received imatinib as upfront therapy. Imatinib was well tolerated in majority of patients. Few experienced manageable side effects like headache, irritability, leukopenia, pain abdomen, vomiting. Duration of treatment was one to three years. GIST is a rare tumor with varied presentations. Surgery is the mainstay of treatment offering chances of cure and revolutionary adjuvant imatinib is well tolerated with mild and manageable side effects in our centre. Being a resource limited centre, affordability for special investigations like IHC (immunohistochemistry) for CD117 (which helps in further confirmation of the diagnosis), remains a challenge for the patient and so does the 2 nd line agent like sunitinib in case of recurrence.
\end{abstract}

Keywords: GIST, Imatinib, Surgery, CD117

\section{INTRODUCTION}

GIST stands for gastrointestinal stromal tumors. It is a rare tumor but most common mesenchymal tumor in the gastrointestinal tract comprising of $0.1-3 \%$ of all GI malignancies. ${ }^{1}$ Origin of GIST is recognized from pacemaker cells of gut also known as interstitial cell of Cajal (ICC) after Spanish neuroanatomist Ramon Y Cajal in 19th century. These cells are present in the muscularis 
propria and around the myenteric plexus. Historically GISTs were frequently misclassified as leiomyoma, leiomyoblastoma, leiomyosarcoma or schwannoma as a result of their histological findings and apparent origin in the muscularis propria layer of the intestinal wall. ${ }^{2}$ However, GISTs are now considered a distinct group of mesenchymal tumors due to its immunohistochemical findings and positivity for CD117. These tumors most commonly arise in stomach followed by small intestine and few case reports of extra gastrointestinal GIST (EGIST) have also been reported. ${ }^{3}$ Most common age of diagnosis is 60 years. $^{4}$ In this retrospective study of 20 cases of GIST reporting in our centre, our aim was to review these patients based on clinical profile, investigations, sites, treatment, histology, IHC analysis and adjuvant treatment received.

\section{CASE SERIES}

Medical records of 20 patients registered in our department were reviewed from hospital based cancer registry from 2014 to 2020. Patients clinical characteristics like age, sex, investigations done like CECT abdomen, upper GI endoscopy, colonoscopy, treatment modalities like type of surgery, histopathological and IHC (CD117 positivity) of resected specimen, adjuvant therapy were reviewed. Prognostic factors like tumor size, mitotic index was studied. Patients were staged using AJCC 8th edition staging and also stratified using NIH risk stratification.

\section{Observations}

GIST was common in males $(\mathrm{N}=13,65 \%)$ than females $(\mathrm{N}=7,35 \%)$ (Table 1). Age group ranged from 25 to 76 years with mean age 51.9 years and median age 50 years.

Abdominal pain $(\mathrm{N}=7,35 \%)$ was the most common presenting complaint followed by abdominal lump $(\mathrm{N}=3$, $15 \%)$. Other symptoms included dysphagia, haematemesis, melena and blood in stools.

Endoscopic/colonoscopy findings varied from extrinsic bulge to polypoidal lesions and few patients had nodular lesions with ulcer. CECT findings revealed heterogeneously enhancing soft tissue density mass/polypoidal mass with exophytic component. Some reports mentioned areas of necrosis within the mass. In one patient presenting with complaint of blood in stools, incidental diagnosis was made with the help of CT angiography which was initially done for suspected GI bleed. Patient had negative endoscopy and colonoscopy findings. CT angiography revealed e/o enhancing mass measuring $4 \times 4.5 \mathrm{~cm}$ with CT value of $124 \mathrm{HU}$ in right sided pelvis (Figure $1 \mathrm{a}-\mathrm{c}$ ). Differential diagnosis of GIST was made.

Stomach was most common site which was involved in half of the patients $(\mathrm{N}=8,40 \%)$ followed by jejunum $(\mathrm{N}=6,30 \%)$, terminal ileum $(\mathrm{N}=2,10 \%)$. Two patients had mass in upper abdomen and exact origin could not be assessed on CT scan. Other sites were esophagus $(\mathrm{N}=1)$ and anorectum $(\mathrm{N}=1)$. Five patients $(\mathrm{N}=5,25 \%)$ had metastatic disease to liver $(\mathrm{N}=4,80 \%$ and lungs $\mathrm{N}=1,20$ $\%)$.

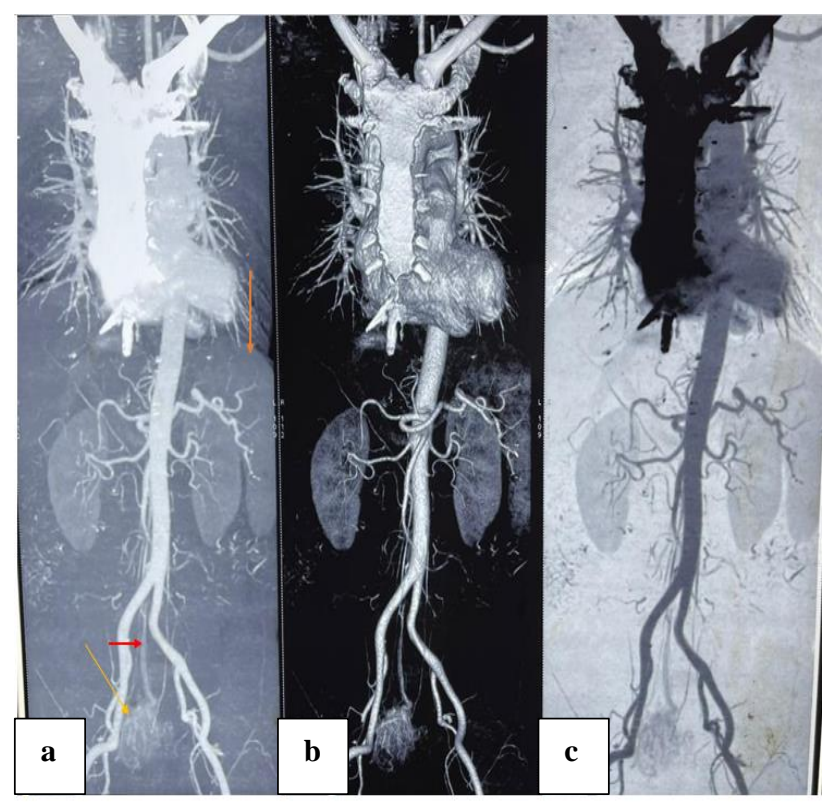

Figure 1: (a) Coronal section I/V contrast $\mathrm{CT}$ angiography image in arterial phase through thorax, abdomen and pelvis showing hyper vascular mass (yellow arrow) right sided pelvis deriving its blood supply from superior mesenteric artery (SMA, red arrow) with enlarged spleen (orange arrow); (b) volume rendered phase in same patient; (c) negative gray shade image in same patient.

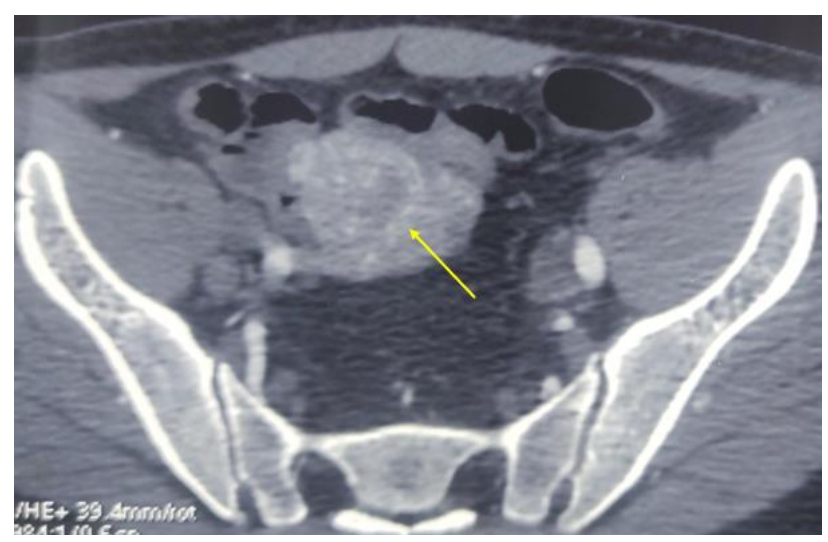

Figure 2: Axial section of I/V contrast enhanced CT scan through pelvis showing heterogeneously enhancing mass in rt pelvis (yellow arrow); mass was arising from jejunum as per operative findings.

Sixteen patients received surgery as the part of upfront treatment $(\mathrm{N}=16,80 \%)$, three patients were unresectable at presentation and received imatinib as primary treatment $(\mathrm{N}=3,15 \%)$. One patient presenting with mass in left hypochondrium and liver metastasis refused any 
sort of treatment advised $(\mathrm{N}=1,5 \%)$. Out of sixteen patients who received surgery as the primary treatment 14 patients underwent $\mathrm{R} 0$ resection, one patient each underwent $\mathrm{R} 1$ and $\mathrm{R} 2$ resection.

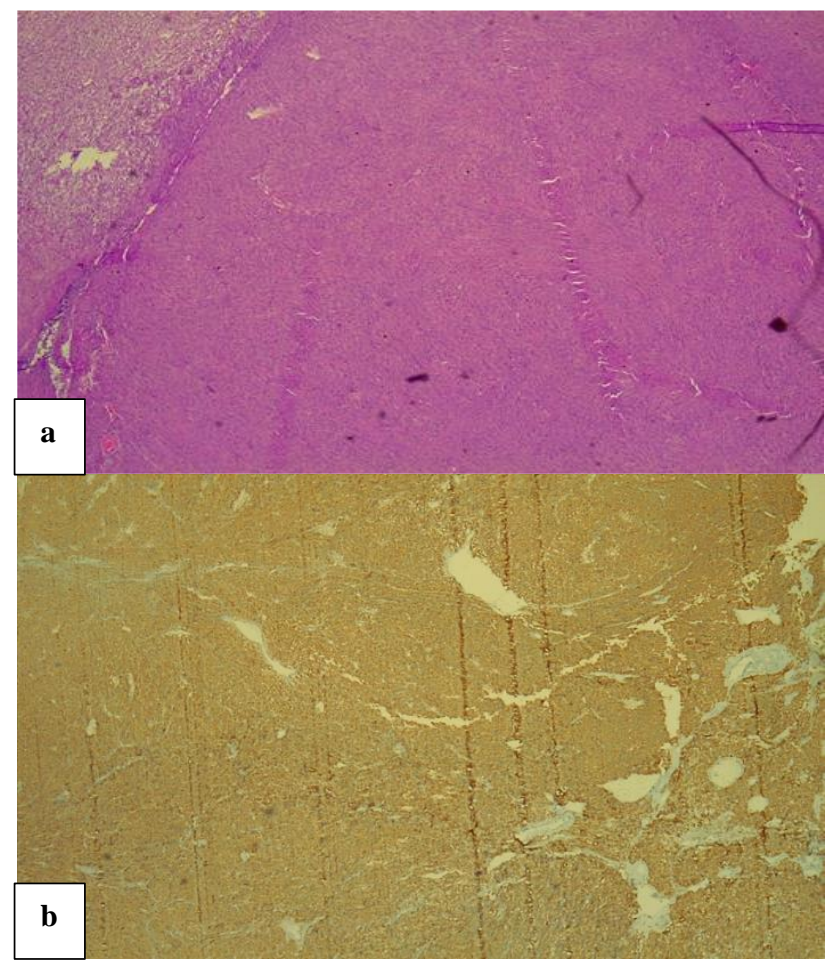

Figure 3: (a) Specimen of GIST terminal ileum showing spindle cells; (b) CD117 positivity by IHC in biopsy specimen of terminal ileum.

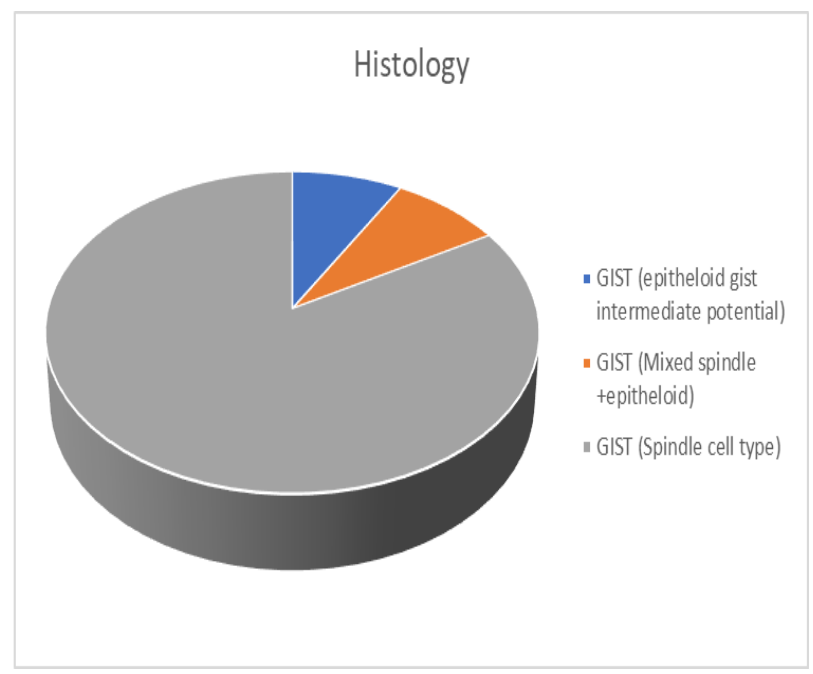

Figure 4: Histology of GIST; spindle cell is the most common variant $(90 \%)$ followed by epithelioid and mixed in rest $10 \%$.

Detailed histopathological examination revealed spindle cell type of GIST (Figure 3 (a)) as the most common histology. One patient had mixed spindle and epithelioid variant, and another had epithelioid histology. Size varied from $2 \mathrm{~cm}$ to $25 \mathrm{~cm}$ in greatest dimension (Table1).
Mitotic Index varied from 2/50 HPF to $30 / 50 \mathrm{HPF}$ (Table 1). As per NIH grouping of risk stratification 12 patients belonged to high risk $(n=12,60 \%)$. Three patients belonged to intermediate risk $(n=3,15 \%)$ and five patients belonged to low risk $(\mathrm{n}=5,25 \%)$ (Table 2). Patients were staged according to AJCC 8th edition of staging. Majority of patients belonged to stage III $(n=11$, $55 \%)$.

IHC was done in 15 patients and all were positive for CD117 (Figure 3 (b)). All post-op patients and unresectable patients $(n=19,95 \%)$ received imatinib 400 $\mathrm{mg}$ as adjuvant therapy except one who refused Rx. Eleven patients had no side effects of treatment. Other side effects comprised of mild leukopenia (WBC 30004000/micro litre), irritability, pain abdomen and headache (Figure 7). Duration of treatment varied between 1 year to 3 years.

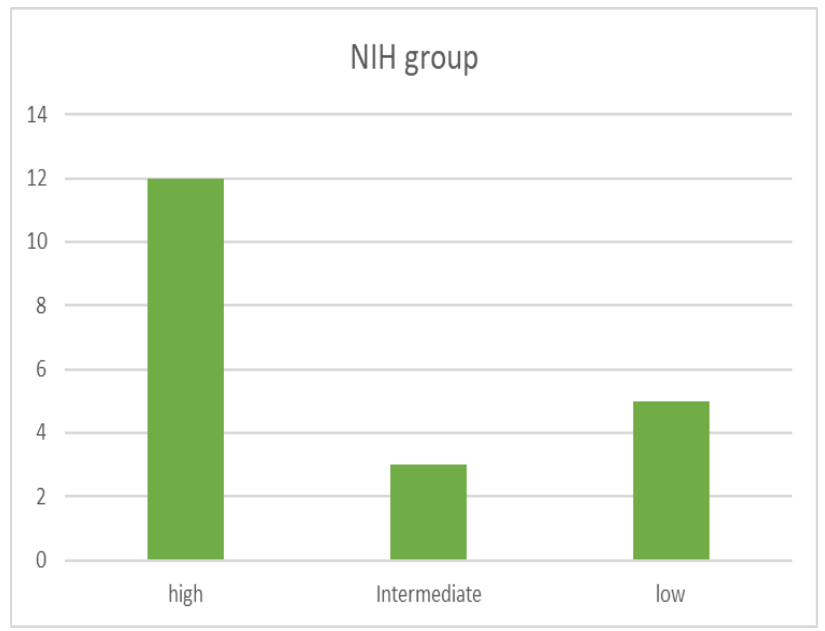

Figure 5: Majority of the patients belonged to high grade according to NIH criteria followed by low and intermediate risk.

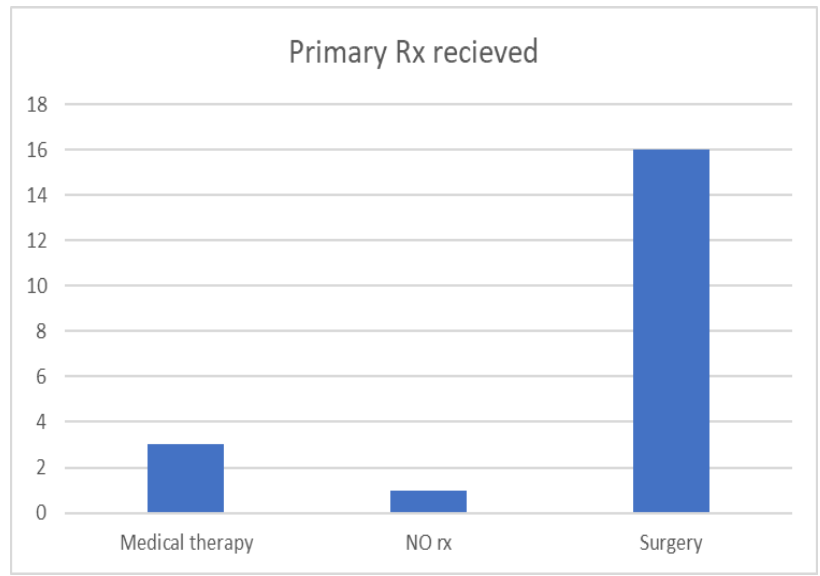

Figure 6: Surgery was the primary treatment received by majority of the patients with GIST; two patients had unresectable disease and were given imatinib as primary treatment and one patient refused treatment of any sort. 


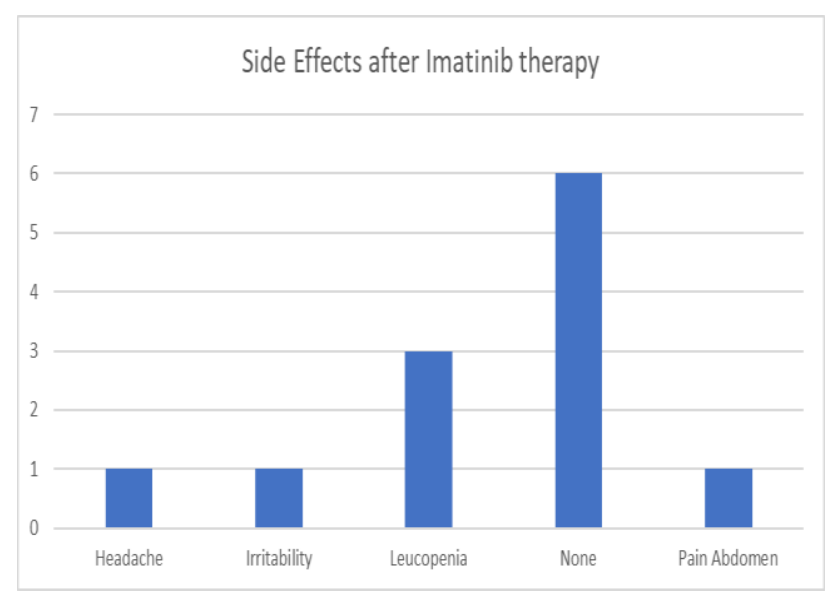

Figure 7: Side effects of tablet imatinib $400 \mathrm{mg}$ once daily dose; majority of patients had no side effects; there were no treatment breaks due to side effects in any patient.

Table 1: Various patient characteristics.

\begin{tabular}{|c|c|c|c|}
\hline \multicolumn{2}{|c|}{ Patients characteristics } & $\begin{array}{l}\text { Number } \\
(\mathbf{N})\end{array}$ & Percentage \\
\hline \multirow{2}{*}{ Sex } & Male & 13 & 65 \\
\hline & Female & 7 & 35 \\
\hline \multirow{2}{*}{ Age } & $<60$ & 14 & 70 \\
\hline & $\geq 60$ & 6 & 30 \\
\hline \multirow{4}{*}{$\begin{array}{l}\text { Tumor } \\
\text { size }(\mathrm{cm})\end{array}$} & $\leq 2$ & 1 & 5 \\
\hline & $2.1-5$ & 5 & 25 \\
\hline & $5.1-10$ & 6 & 30 \\
\hline & $>10$ & 8 & 40 \\
\hline \multirow{3}{*}{$\begin{array}{l}\text { Mitotic } \\
\text { index }\end{array}$} & $\leq 5 / 50 \mathrm{HPF}^{*}$ & 11 & 55 \\
\hline & 5.1-10/50 HPF & 7 & 35 \\
\hline & $>10 / 50 \mathrm{HPF}$ & 2 & 10 \\
\hline \multirow{3}{*}{$\begin{array}{l}\text { Distant } \\
\text { metastasis }\end{array}$} & Liver & 4 & 20 \\
\hline & Lungs & 1 & 5 \\
\hline & No mets & 15 & 75 \\
\hline
\end{tabular}

*High power field.

Table 2: NIH GIST consensus criteria.

\begin{tabular}{|lll|}
\hline Risk category & $\begin{array}{l}\text { Tumor size } \\
(\mathrm{cm})\end{array}$ & $\begin{array}{l}\text { Mitotic } \\
\text { count/50 HPF }\end{array}$ \\
\hline Very low risk & $<2$ & $<5$ \\
\hline Low risk & $2-5$ & $<5$ \\
\hline \multirow{2}{*}{ Intermediate risk } & $<5$ & $6-10$ \\
\cline { 2 - 3 } & $5-10$ & $<5$ \\
\hline \multirow{2}{*}{ High risk } & $>5$ & $>5$ \\
\cline { 2 - 3 } & $>10$ & Any mitotic rate \\
\cline { 2 - 3 } & Any size & $>10$ \\
\hline
\end{tabular}

\section{DISCUSSION}

GIST is rare but most common mesenchymal tumors of the gastrointestinal tract. They may originate from stomach, small intestine, large intestine, mesentery, omentum, esophagus. The incidence of GIST in India was unknown and its treatment strategy in our country was largely derived from studies in other global populations. ${ }^{5}$ Clinical presentation of the patient reporting to the hospital depends upon site from where it arises. GIST arising from upper GI tract may present as upper dysphagia, haematemesis, nausea, vomiting. Tumors located in lower GI tract present with abdominal lump melena, abdominal pain. Owing to big size of the tumor abdominal lump can be one of the presenting features. Retrospective analysis of Chilean and Mexican GIST registries have reported stomach to be most common site of GIST. ${ }^{6}$ In this study in majority of the patients mass originated from stomach with abdominal pain as the most common presenting complaint. In a study by Minhas et al as well stomach was the most common site of the tumor. ${ }^{7}$ In our study GIST was more common in males than females consistent with the studies conducted in other parts of the country.,8

Age of the patients varied from 25 years to 76 years with 50 years as median age of diagnosis. The various sites of lesion in our study were stomach, ileum, jejunum, esophagus, rectum and in two patients the exact origin could not be ascertained.

CECT of abdomen and pelvis aids in diagnosis along with upper GI endoscopy and colonoscopy. However excision and histopathological examination of the tumor gives exact confirmation of diagnosis. Incidental diagnosis in patients presenting with suspected GI bleed was also encountered. In our study in a patient with negative bi-directional endoscopy (upper GI endoscopy and colonoscopy) for tumor underwent CT angiography which revealed a hyper vascular mass in right side of the pelvis with CT density of $124 \mathrm{HU}$ deriving its arterial supply from superior mesenteric artery (Figure 1). Patient underwent exploratory laparotomy along with resection of growth bearing segment of jejunum. Detailed histopathological examination revealed GIST with positivity for CD117, DOG1, CD34, SMA and KI67 in $5 \%$ of the cells. CT angiography was only recommended for patients with melena when no abdominal mass was palpable and the examination of upper GI was negative. It helped us to identify the supplying arteries, differentiate benign from malignant tumors and define their size, range and origin, even if tumors grow exophytically or endophytically. ${ }^{9}$

Histologically GIST can be of three types with most common being the spindle cell type $(70 \%)$ followed by epithelioid type (20\%) and the rest of them $(10 \%)$ are mixed spindle cell and epithelioid type. In this study spindle cell was the most common type $(\mathrm{N}=18,90 \%)$ and followed by epithelioid $(\mathrm{N}=1,5 \%)$ and mixed histology $(\mathrm{N}=1,5 \%)$ in one patient each.

IHC marker like CD117 are considered confirmatory test for the diagnosis of GIST but cannot be considered gold standard as $6 \%$ of the patients may be CD117 negative 10 . 
In this study IHC was done in 15 patients and all were positive for CD117. IHC was not done in 5 patients due to affordability issues.

Age ( $>60$ years), tumor size ( $>10$ having worse survival), mitotic index (MI >10/50 HPF), tumor site (small intestine), occurrence of curative resection and postoperative imatinib were considered as valuable factors in the prognostic assessment of GIST in a study by Liu et al. ${ }^{11}$ The patient characteristics are shown in Table 1.

Risk stratification of GIST is done with the help of NIH criteria by Fletcher and colleagues who categorized the patients into very low, low, intermediate and high-risk groups by considering the size and mitotic activity of the tumor (Table 2). In this study majority of the patients belonged to the high-risk category and thereby higher risk of recurrence. One patient with high risk and stage IIIB had recurrence post three years of targeted therapy and was managed with re-excision and rechallenge with same drug.

Staging is done with the help of AJCC 8th edition which has separate stage grouping criteria for gastric/omental GIST and esophageal/small intestinal/colorectal/ mesenteric/peritoneal GIST. It was a TNM (tumor, node, metastasis) staging along with consideration of mitotic rate. ${ }^{12}$ In this study majority of patients belonged to stage III.

Surgery was the cornerstone of the treatment of GIST and curative resections offer prognostic significance. ${ }^{11}$ Madhavan et al in their study discussed the surgical procedures performed which varied from local resections (e.g. open/laparoscopic sleeve gastrectomy open/laparoscopic wedge resection), anatomical resections (subtotal /total/proximal partial gastrectomy/esophagogastrrectomy) or extended resections (e.g. open sleeve gastrectomy+distal pancreatectomy+splenectomy, open sleeve gastrectomy+wedge resection diaphragm, total gastrectomy+en bloc resection of diaphragm). In this study the surgeries included APR, bilroth type gastrectomy, distal radical gastrectomy, exploratory laparotomy, sleeve gastrectomy excision of mass, E/L resection of tumor bearing segment of ileum, E/L resection of tumor bearing segment of jejunum, E/L sleeve gastrectomy excision of mass, sleeve resection of lesser curvature,wide local excision. In sixteen patients who received surgical treatment fourteen $(\mathrm{N}=14,87.5 \%)$ had $\mathrm{R} 0$ resection which is the ultimate aim of the curative surgery. Laparoscopic surgery (wedge resection) was indicated if the GIST was less than $5 \mathrm{~cm}$ in size. ${ }^{14}$

Medical management of GIST includes imatinib mesylate which was initially developed for the treatment of chronic myelogenous leukaemia, (CML) as it inhibits the BCR$\mathrm{ABL}$ fusion protein. ${ }^{15}$ Imatinib has been used in neoadjuvant setting where R0 resections are unlikely.
Preoperative imatinib could be useful to improve curative resections and reduce surgical morbidity. The optimal duration of preoperative therapy is unknown, hence, imatinib may be continued until maximal response. ${ }^{16}$ Standard of care for primary resectable localized gastric GISTs was surgery followed by postoperative radiologic surveillance for recurrence. As many patients develop recurrence after resection, imatinib was indicated in the postoperative setting to reduce recurrence. Adjuvant imatinib $400 \mathrm{mg}$ daily for resectable GIST should be considered in high-risk disease and in any tumor size/any mitotic index in the presence of tumor rupture. ${ }^{16}$ Joensuu et al reported results of an open-label phase study conducted in 24 hospitals in Finland, Germany, Norway, and Sweden. ${ }^{3}$ They concluded that compared with 12 months of adjuvant imatinib, 36 months of imatinib improved recurrence free survival (RFS) and overall survival (OS) of GIST patients with a high risk of GIST recurrence. ${ }^{17}$ In scenario of recurrent/metastatic GIST, $400 \mathrm{mg}$ dose is standard of care in c-kit positive patients. Patients having kit exon nine mutations do better on the higher dose of imatinib $800 \mathrm{mg}$ as per Indian council of medical research (ICMR) consensus document for the management of gastrointestinal stromal tumors by Shrikhande et al. ${ }^{16}$ In metastatic GIST treatment should be continued indefinitely. Tumor response should be assessed at 3 monthly intervals to begin with and then 6 monthly thereafter if response was ongoing. In cases of progression on imatinib, the standard approach was to increase the dose from $400 \mathrm{mg}$ to $800 \mathrm{mg}$ daily.

In cases of progression or intolerance on imatinib, 2nd line treatment with sunitinib can be considered at the dose of $50 \mathrm{mg}$. Rx regimen of sunitinib consists of 4 weeks on-2 weeks off schedule. Other regimen was continuous dosing at $37.5 \mathrm{mg}$ which was better tolerated and equally effective. ${ }^{18}$ Third-line treatment after failure on sunitinib is regorafenib. Demetri et al in a phase III trial concluded that oral regorafenib can provide a significant improvement in progression-free survival compared with placebo in patients with metastatic GIST after progression on standard treatments. ${ }^{19}$ Another resort for these patients was participation in a clinical trial. In this study all patients were given $400 \mathrm{mg}$ of imatinib. One patient had progression but could not afford sunitinib, so the patient was rechallenged with the same drug. Imatinib was well tolerated by majority of the patients with some having minor side effects but there were no treatment breaks due to that (Figure 7).

\section{CONCLUSION}

GISTs are rare entities with surgical resection offering chance of cure. Imatinib therapy is useful in neoadjuvant, adjuvant and metastatic setting with sunitinib and regorafenib available for progression as second and thirdline drugs, respectively. Mitotic index and tumor size are important parameters to be reviewed in histopathological examination as they predict the recurrence. IHC markers like CD117 are diagnostic but can be negative in few 
patients. Due to non-affordability costlier drugs like sunitinib could not be given in one patient with progression. A multidisciplinary approach between a radiologist, gastroenterologist, pathologist can help in ascertaining quick diagnosis and then further surgeon and medical oncologist can collaborate on the treatment planning to provide best treatment and outcome for GIST patients.

\section{Funding: No funding sources \\ Conflict of interest: None declared \\ Ethical approval: Not required}

\section{REFERENCES}

1. Ahmed M. Recent advances in the management of gastrointestinal stromal tumor. World J Clin Cases. 2020;8(15):3142-55.

2. El-Menyar A, Mekkodathil A, Al-Thani H. Diagnosis and management of gastrointestinal stromal tumors: an up-to-date literature review. J Cancer Res Ther. 2017;13(6):889-900.

3. Alkhatib L, Albtoush O, Bataineh N, Gharaibeh K, Matalka I, Tokuda Y. Extragastrointestinal stromal tumor (EGIST) in the abdominal wall: case report and literature review. Int J Surg Case Rep. 2011;2(8):253-5.

4. Alvarado-Cabrero I, Vázquez G, Santiesteban FIS, Hernández-Hernández DM, Pompa AZ. Clinicopathologic study of 275 cases of gastrointestinal stromal tumors: the experience at 3 large medical centers in Mexico. Ann Diagn Pathol. 2007;11(1):39-45.

5. Minhas S, Bhalla S, Jauhri M, Ganvir M, Aggarwal S. Clinico-pathological characteristics and mutational analysis of gastrointestinal stromal tumors from India: a single institution experience. Asian Pac J Cancer Prev. 2019;20(10):3051-5.

6. Calderillo G, Muñoz-Medel M, Carbajal E, Córdova-Delgado M, Durán D, Retamal IN, et al. Retrospective analysis of chilean and mexican gi stromal tumor registries: a tale of two Latin American realities. JCO Glob Oncol. 2020;6:64757.

7. Minhas S, Bhalla S, Jauhri M, Ganvir M, Aggarwal S. Clinico-pathological characteristics and mutational analysis of gastrointestinal stromal tumors from India: a single institution experience. Asian Pac J Cancer Prev. 2019;20(10):3051-5.

8. Malik K, Seshadri RA, Sundersingh S, Dhanushkodi M. Gastrointestinal stromal tumours (GIST): Indian experience of rare malignancy. Indian J Surg Oncol. 2020;11(3):348-54.

9. Fang SH, Dong DJ, Zhang SZ, Jin M. Angiographic findings of gastrointestinal stromal tumor. World $\mathbf{J}$ Gastroenterol. 2004;10(19):2905-7.
10. Tzen CY, Mau BL. Analysis of CD117-negative gastrointestinal stromal tumors. World J Gastroenterol. 2005;11(7):1052-5.

11. Liu X, Qiu H, Zhang P, Feng X, Chen T, Li Y, et al. Prognostic factors of primary gastrointestinal stromal tumors: a COHORT study based on highvolume centers. Chin J Cancer Res. 2018;30(1):6171.

12. Park $\mathrm{CH}$, Kim GH, Lee BE, Song GA, Park DY, Choi KU, et al. Two staging systems for gastrointestinal stromal tumors in the stomach: which is better? BMC Gastroenterol. 2017;17(1):141.

13. Madhavan A, Phillips AW, Donohoe CL, Willows RJ, Immanuel A, Verril $M$, et al. Surgical management of gastric gastrointestinal stromal tumours: comparison of outcomes for local and radical resection. Gastroenterol Res Pract. 2018;2018:2140253.

14. Kong SH, Yang HK. Surgical treatment of gastric gastrointestinal stromal tumor. J Gastric Cancer. 2013;13(1):3-18.

15. Ksienski D. Imatinib mesylate: past successes and future challenges in the treatment of gastrointestinal stromal tumors. Clin Med Insights Oncol. 2011;5:365-79.

16. Shrikhande SV, Sirohi B, Barreto SG, Chacko RT, Parikh PM, Pautu J, et al. Indian council of medical research consensus document for the management of gastrointestinal stromal tumors. Indian $\mathbf{J} \mathrm{Med}$ Paediatr Oncol. 2014;35(4):244-8.

17. Joensuu H, Eriksson M, Hall KS, Hartmann JT, Pink D, Schütte J, et al. One vs three years of adjuvant imatinib for operable gastrointestinal stromal tumor: a randomized trial. JAMA. 2012;307(12):1265-72.

18. George S, Blay JY, Casali PG, Cesne AL, Stephenson P, Deprimo SE, et al. Clinical evaluation of continuous daily dosing of sunitinib malate in patients with advanced gastrointestinal stromal tumour after imatinib failure. Eur J Cancer. 2009;45(11):1959-68.

19. Demetri GD, Reichardt P, Kang YK, Blay J, Rutkowski P, Gelderblom H, et al. Efficacy and safety of regorafenib for advanced gastrointestinal stromal tumours after failure of imatinib and sunitinib (GRID): an international, multicentre, randomised, placebo-controlled, phase 3 trial. Lancet. 2013;381(9863):295-302.

Cite this article as: Sharma J, Negi A, Gupta M, Fotedar V, Vats S, Dhiman P. Clinical, pathological, radiological characteristics, risk stratification and immunohistochemistry profile of gastrointestinal stromal tumors treated in a tertiary cancer centre located in Sub-Himalayan region: institutional experience of 20 patients and review of literature. Int Surg J 2021;8:2414-9. 